\title{
Projeto de Pesquisa - suas funções e partes constitutivas ${ }^{1}$
}

José D'Assunção Barros²

\begin{abstract}
Resumo
O artigo propõe-se a discutir, de modo didático, aspectos introdutórios relacionados à elaboração de um Projeto de Pesquisa. Discutem-se os motivos e razões para a utilização deste recurso de planejamento de pesquisa que é o Projeto, e as partes que o constituem. O texto remete a um livro mais aprofundado publicado pelo autor, e apresenta este livro como referência única devido à singularidade do artigo, que é a de apresentar-se como convite para que o leitor procure esta obra para maiores aprofundamentos.
\end{abstract}

Palavras-chave: projeto, pesquisa, metodologia, teoria, planejamento.

\begin{abstract}
The article proposes to discuss, in a didactic way, introductory aspects pertinent to the elaboration of a Research Project. They are discussed the motives and reasons for the utilization of this resource of research planning, that is the Project, and they are discussed also the parts that constitute a Project. The text refers to a book more developed that was published by the author, and presents this books as reference, in order to attend to its singularity, that is to invite the reader to search this work for more deep approach.
\end{abstract}

Keywords: project, research, methodology, theory, planning.

\section{Para que escrever um Projeto de Pesquisa?}

Iniciar uma Pesquisa, em qualquer campo do conhecimento humano, é partir para uma viagem instigante e desafiadora. Mas trata-se, decerto, de uma viagem diferente, onde já não se pode contar com um caminho preexistente que bastará ser percorrido após a decisão de partir. Se qualquer viagem traz consigo uma sensação de novidade e de confronto com o desconhecido, a viagem do conhecimento deparase adicionalmente com a inédita realidade de que a estrada e o percurso da Pesquisa devem ser construídos a cada momento pelo próprio pesquisador. Até mesmo a escolha do lugar a ser alcançado ou visitado não é mera questão de apontar o dedo para um ponto do mapa, pois este lugar deve ser, também ele, construído a partir da imaginação e da criatividade do investigador.

Delimitado o tema, o problema a ser investigado, e os objetivos a serem atingidos, o pesquisador deverá em seguida produzir ou constituir os seus próprios materiais - pois não os encontrará prontos em uma agência de viagens ou em uma loja de artigos apropriados para a ocasião - e isto inclui desde

\footnotetext{
${ }^{1} \mathrm{O}$ artigo aqui apresentado sintetiza o capítulo inicial de um livro publicado pelo autor: BARROS, José D'Assunção, O Projeto de Pesquisa em História (Petrópolis: Vozes, 2008, $4^{\mathrm{a}}$ edição).

${ }^{2}$ Doutor em História Social pela Universidade Federal Fluminense (UFF). Professor visitante da Universidade Federal de Juiz de Fora (Juiz de Fora) e Professor Titular da Universidade Severino Sombra (USS) de Vassouras (Brasil). E-mail: jose.assun@globo.com
} 
os instrumentos necessários à empreitada até os modos de utilizá-los. É assim que, se qualquer viagem necessita de um cuidadoso planejamento - de um roteiro que estabeleça as etapas a serem cumpridas e que administre os recursos e o tempo disponível - mais ainda a viagem da Pesquisa Científica necessitará deste instrumento de planejamento, que neste caso também será um instrumento de elaboração dos próprios materiais de que se servirá o viajante na sua aventura em busca da construção do conhecimento. Este é o papel do Projeto na Pesquisa Científica.

O Projeto de Pesquisa deve ser, naturalmente, um instrumento flexível, pronto a ser ele mesmo reconstruído ao longo do próprio percurso empreendido pelo pesquisador. Se o conhecimento é produto da permanente interação entre o pesquisador e o seu objeto de estudo, como tende a ser considerado nos dias de hoje, as mudanças de direção podem ocorrer com alguma freqüência, à medida que esta interação se processa e modifica não apenas o objeto de estudo, mas o próprio estudioso.

Ao se deparar com novas fontes, ao imaginar novas hipóteses, ao se confrontar com as inevitáveis dificuldades, ao produzir novos vislumbres de rumos possíveis, ou ao amadurecer no decorrer do próprio processo de pesquisa, o investigador deverá estar preparado para lidar com mudanças, para abandonar roteiros, para antecipar ou retardar etapas, para se desfazer de um instrumento de pesquisa em favor do outro, para repensar as esquematizações teóricas que até ali haviam orientado o seu pensamento. Neste sentido, todo Projeto é provisório, sujeito a mutações, inacabado.

Diante deste caráter provisório e inacabado do Projeto, o pesquisador iniciante freqüentemente se vê tentado a supor que elaborar um Projeto é mera perda de tempo, e que melhor seria iniciar logo a pesquisa. Da mesma forma, o estudioso que acaba de ingressar em um Programa de Mestrado, o estudante que está em vias de elaborar a sua Monografia de final de curso ou de pós-graduação, ou o aluno envolvido em uma pesquisa de Iniciação Científica, não raro se põem a perguntar se não seria mais adequado começar já a escrever os capítulos de sua dissertação, à medida que vai levantando e analisando os seus materiais (como na História ou na Sociologia), ou à medida que vai realizando os seus experimentos (neste último caso, considerando ciências como a Física ou a Química). Se ele passa a elaborar o seu Projeto, a contragosto, é porque se acha obrigado a isto institucionalmente, uma vez que deverá defendê-lo a certa altura do seu curso em um evento que nas universidades brasileiras chama-se "exame de qualificação".

Já com relação ao pesquisador que participa de um Programa de Pós-Graduação em nível de Doutorado, este, na maior parte dos casos, já deve ter elaborado o seu Projeto antes de ter ingressado no Programa - e neste caso o Projeto terá assumido para ele, para além do papel de uma exigência institucional, a função de uma "carta de intenções" a partir da qual ele procurou convencer a banca examinadora de que era um candidato interessante para o Programa.

Por outro lado, para além dos ambientes acadêmicos e universitários, com freqüência uma pesquisa é proposta pelo seu executante para ser financiada por organizações nacionais e internacionais, por institutos e órgãos de fomento à pesquisa, e também por empresas da caráter privado ou estatal. Os professores que atuam nos meios universitários também devem, na maior parte das vezes, registrar as pesquisas que estão realizando como parte de suas atividades docentes. Em todos estes casos, a elaboração do Projeto de Pesquisa se apresenta novamente como uma exigência necessária, e a incapacidade de atender a esta exigência de maneira minimamente satisfatória pode implicar perda de oportunidades profissionais importantes.

Em que pesem estes aspectos institucionais de que se pode ver revestido, um Projeto de Pesquisa é na verdade muito mais do que isto. Assim, contrariamente à falsa idéia de que o Projeto é meramente uma exigência formal e burocrática, ou de que se constitui apenas naquele recurso necessário para a Instituição selecionar candidatos a pesquisadores ou avaliar o seu desempenho, o estudioso mais amadurecido sabe que o Projeto é efetivamente uma necessidade da própria pesquisa. Sem o 
Projeto, ele sabe que a sua viagem se transformará em uma caminhada a ermo, que os recursos em pouco tempo estarão esgotados por falta de planejamento, e que os próprios instrumentos necessários para iniciar a viagem, para dar um passo depois do outro, sequer chegarão a ser elaborados. Ademais, sempre é bom ressaltar que uma das principais finalidades do Projeto, além de visar a definição precisa do que será pesquisado, é registrar do porquê e do para que realizar a pesquisa (isto é, a sua responsabilidade social), o que, via de regra, conforme veremos, deverá ser esclarecido em um item bastante específico do Projeto que é a 'Justificativa'.

Retomando a questão de que o Projeto corresponde à própria constituição dos materiais e rumos a serem trilhados pela Pesquisa, sem o Projeto, o pesquisador mais experiente sabe que não existe sequer um caminho, uma vez que este deve ser construído gradualmente a partir de materiais elaborados pelo próprio pesquisador - sendo a elaboração do Projeto simultaneamente o primeiro passo da caminhada e o primeiro instrumento necessário para se pôr a caminho. O Projeto de Pesquisa, desta maneira, mostra-se a este pesquisador precisamente um ganho de tempo, um agilizador da pesquisa, um eficaz roteiro direcionador, um esquema prévio para a construção dos materiais e técnicas que serão necessários para alcançar os objetivos pretendidos.

O "Quadro 1" procura resumir algumas das principais funções de um Projeto de Pesquisa.
Certamente que a principal função de um Projeto de Pesquisa é a de apresentar a sua responsabilidade social - considerando que o Projeto é também um elo entre o Pesquisador e a sociedade que o acolhe, seja no que se refere àqueles que possibilitarão a produção e desenvolvimento da pesquisa enquanto base de apoio ou mesmo como objeto de análise, para o caso das Ciências Sociais e Humanas, seja no que se refere à própria sociedade para a qual se direcionam os resultados da Pesquisa. O Projeto, naturalmente, é registro de uma relevância social e acadêmica, de um compromisso com a sociedade e a comunidade científica. Reconhecendo esta dimensão fundamental de um Projeto de Pesquisa, estaremos, em seguida, considerando aquelas funções do Projeto que se relacionam mais diretamente com o próprio planejamento e desenvolvimento da Pesquisa.

No esquema proposto, encontraremos as já mencionadas funções formais ou burocráticas, que os pesquisadores iniciantes confundem com a única razão de ser do Projeto, mas também as funções operacionais, que são inerentes à própria realização de uma Pesquisa em si mesma. Assim, se o Projeto é uma "carta de intenções" (1) onde o pesquisador exibe a sua proposta investigativa para uma instituição acadêmica ou científica, e se ele é um "item curricular" nas instituições de PósGraduação (2), o Projeto é também um poderoso instrumento que cumpre as funções de "direcionador da pesquisa" (3).

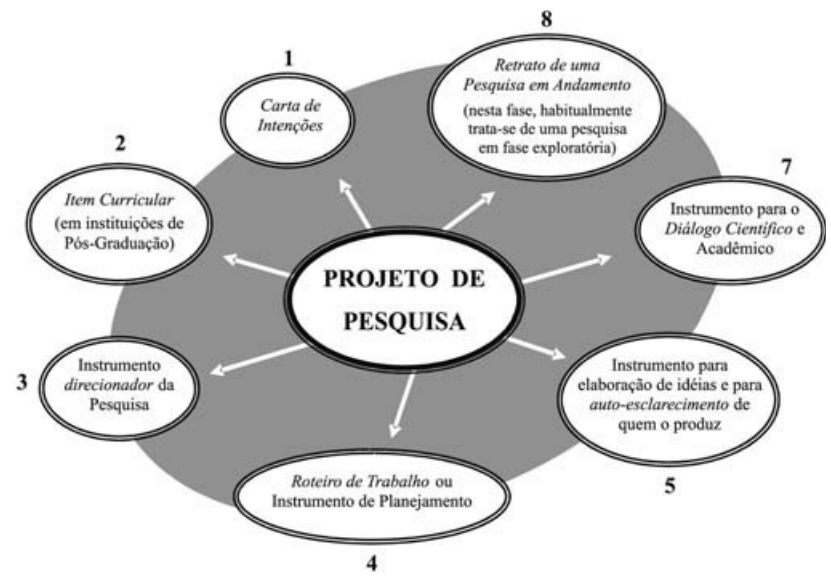

Quadro 1 - Funções do Projeto de Pesquisa 
Neste último particular, o pesquisador que pretenda iniciar sem um Projeto a sua viagem de construção do conhecimento, cedo perceberá que o próprio tema lhe parece fugir constantemente. Facilmente o pesquisador pode se pôr a perder em uma floresta temática, que lhe oferece mil direções e possibilidades, até que perceba que, dentro de um tema mais amplo, é preciso recortar, criar um problema, estabelecer uma direção, e que o Projeto vai lhe permitir precisamente a efetivação destes múltiplos recortes que tornarão a sua pesquisa possível, viável e relevante.

Esta constituição gradual e sistemática de um objeto de pesquisa não necessita apenas de uma direção e de um recorte delimitador, mas também de um planejamento. Aqui, o Projeto vem trazer outra contribuição, uma vez que em uma de suas instâncias ele se constitui em um "roteiro de trabalho" ou em um instrumento de planejamento (4) sem o qual o pesquisador desperdiçaria os seus recursos, perdendo-se em uma investigação não sistematizada para ficar a meio caminho dos objetivos que sequer chegou a explicitar de maneira mais clara para si mesmo.

Sobretudo, o Projeto é um eficaz "instrumento para elaboração de idéias" e para auto-esclarecimento de quem o produz (5). Ao elaborar um quadro teórico ou ao pensar metodologias, ao construir hipóteses e fixar objetivos, ao empreender uma revisão bibliográfica que colocará o pesquisador diante da literatura já existente sobre o assunto, o Projeto vai gradualmente esclarecendo aquele que o produz, dando-lhe elementos para articular melhor as suas idéias e confrontálas com o que já foi feito naquele campo de conhecimento.

Mais ainda, o Projeto permite que a pesquisa em andamento seja exposta aos olhares de outros pesquisadores, sejam professores e profissionais mais experientes, que incluem o orientador da dissertação ou da tese, sejam os colegas de mesmo nível, também capazes de contribuir significativamente para uma pesquisa que, sabe-se muito bem, nunca é um trabalho exclusivamente individual. O Projeto torna-se, desta maneira, um instrumento para o "diálogo científico e acadêmico" (6).
Alguns destes diálogos, em se tratando das pesquisas de Pós-Graduação, encontram precisamente o seu lugar nos momentos em que o pesquisador expõe o seu Projeto a professores e colegas nos vários seminários que habitualmente constituem parte dos itens curriculares de um curso de Mestrado ou de Doutorado. O próprio "Exame de Qualificação" é precisamente um momento maior nesta rede permanente de diálogos - um momento algo ritualizado em que o pesquisador apresenta o seu trabalho a alguns professores para receber críticas e sugestões que o ajudarão a aperfeiçoar o seu trabalho e a encontrar novos caminhos.

O Projeto cumpre, desta forma, oferecer o "retrato de uma pesquisa em andamento" (7). Neste momento, em se tratando de uma pesquisa que visa a elaboração de uma Dissertação de Mestrado, é lícito chamar o projeto de "Projeto de Dissertação" (ao invés de "Projeto de Pesquisa", expressão que implicaria uma investigação que ainda está por se realizar ou que, no máximo, anunciaria procedimentos ainda exploratórios). No caso de um "Projeto de Dissertação", que o estudante de mestrado apresenta já na metade do seu curso, a Pesquisa já deve se encontrar em estágio mais avançado e definido, e daí a pertinência desta mudança de designação.

Deve-se mencionar ainda que, neste e em outros casos, é aconselhável, ou mesmo imprescindível, acrescentar ao Projeto um "Plano de Capítulos", no qual devem estar sumariados, de modo sintético e preliminar, os capítulos pretendidos para o texto final da Dissertação de Mestrado ou Tese. Em tempo: este "plano de capítulos" é também provisório, sujeito a mudanças e redefinições, e as próprias sugestões recebidas pela banca examinadora podem contribuir para este redirecionamento que poderá conduzir a uma nova organização de capítulos.

\section{As partes de um Projeto de Pesquisa}

Conforme pudemos ver, o Projeto cumpre múltiplas funções e finalidades no trabalho de Pesquisa. Ele procura antecipar algumas perguntas fundamentais relacionadas à Pesquisa proposta, tanto no sentido de dar uma 
satisfação a terceiros (quando for o caso) como no sentido de promover um auto-esclarecimento para o próprio pesquisador e um delineamento preciso do recorte temático, de cada etapa, de cada instrumento, de cada técnica a ser abordada. Assim, ele responde de antemão às seguintes perguntas relacionadas à pesquisa proposta: $\mathrm{O}$ que se pretende fazer? Por que fazer? Para que fazer? A partir de que fundamentos? Com o que fazer? Como fazer? Com que materiais? A partir de que diálogos? Quando fazer?

Cada uma destas perguntas remete, em princípio, a uma parte específica do Projeto - a uma espécie de compartimento redacional onde o pesquisador procura esclarecer de maneira clara e precisa, para os outros ou para si mesmo, as várias instâncias que devem alicerçar o seu trabalho (Quadro 2).

"O que fazer?", por exemplo, é uma pergunta que se busca esclarecer logo de princípio, na "Introdução" do Projeto e, eventualmente, em um capítulo denominado 'Delimitação Temática' (1) ou 'Exposição do Problema' (estes nomes variam muito, de instituição a instituição, e não devem ser tomados como parâmetros absolutos). Veremos mais adiante que a resposta a esta pergunta deve sofrer sucessivas delimitações, bem como integrar recortes simultâneos que podem remeter a um tempo, a um espaço, a um problema investigado. Por ora, de uma maneira um tanto simplificada, diremos que é precisamente aqui que o pesquisador deve esclarecer ao seu leitor qual é o objeto de sua investigação ou da sua realização científica.

"Por que fazer?" é uma pergunta importante, que interessa particularmente àqueles que irão decidir se o seu projeto deve prosseguir, se deve ser financiado, se pode ser aceito em um programa de pesquisa ou de PósGraduação. O capítulo do Projeto que busca esclarecer isto, de forma bem convincente e argumentativa, denomina-se, habitualmente, 'Justificativa' (2). Não raro, também acrescenta-se a esta denominação as palavras 'relevância' ou 'viabilidade', que no fundo não são mais do que aspectos específicos de uma 'justificativa' no seu sentido mais amplo.

"Para que fazer?" vincula-se ao estabelecimento de objetivos a atingir - dando origem a um capítulo bastante conciso que se refere às finalidades a serem alcançadas, freqüentemente enunciadas em ordem numérica e da maneira mais simples possível. Este capítulo recebe, normalmente, o título de "Objetivos" (3).

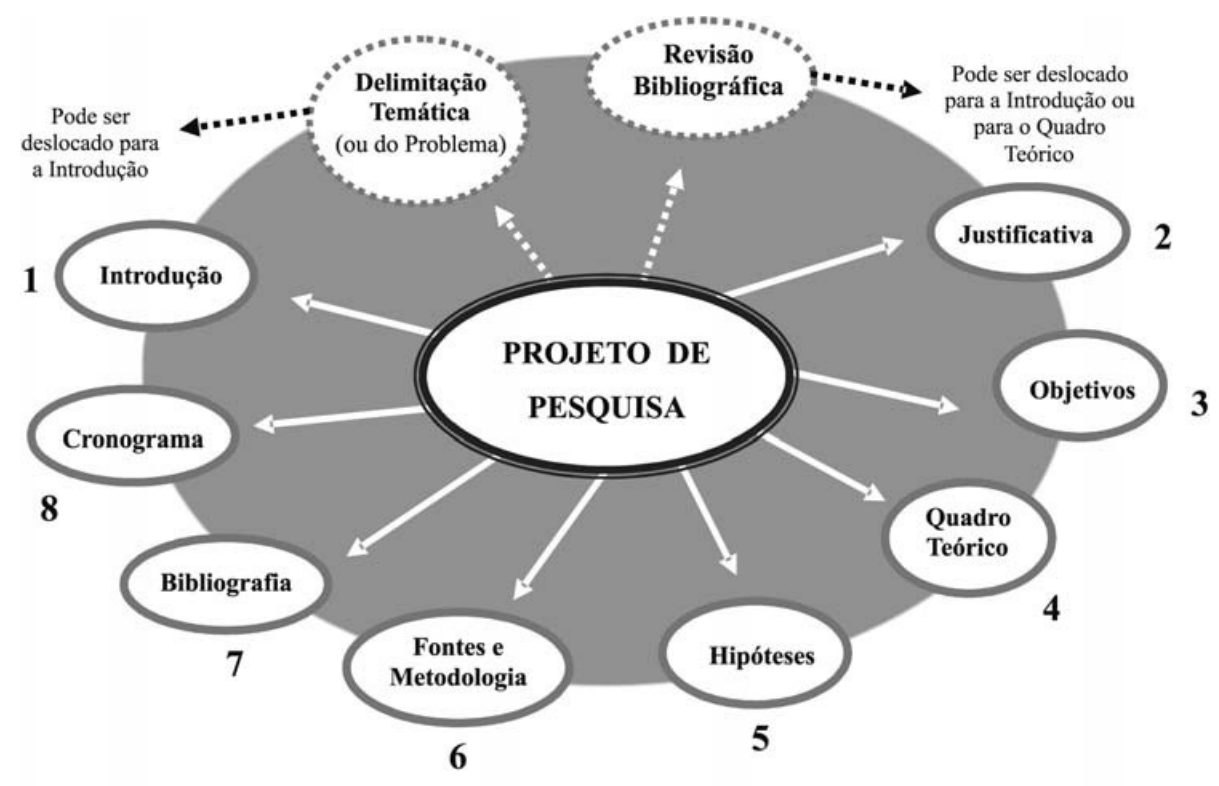

Quadro 2 - As partes de um Projeto de Pesquisa 
"A partir de que fundamentos?" remete a todo um conjunto de possibilidades teóricas ou mesmo de visões de mundo que, pelo menos em parte, o pesquisador já deve trazer consigo ao iniciar a sua viagem produtora de conhecimento. O capítulo que busca concentrar a referência a estes aspectos fundamentais, verdadeiros alicerces mentais que nortearão as ações e as escolhas feitas pelo pesquisador, denomina-se "Quadro Teórico" (4). Trata-se aqui, de definir desde as filiações mais amplas, até os conceitos, expressões e categorias que serão utilizados na elaboração reflexiva e na sua exposição de resultados.

"Com o que fazer?" e "Como fazer?" são indagações que reenviam respectivamente aos instrumentos e às técnicas de pesquisa. De fato, um "instrumento" é aquilo com o que se faz, e remete aos recursos de natureza material ou mesmo abstrata que serão empregados como verdadeiras ferramentas para a pesquisa. Neste caso, são 'instrumentos' um cronômetro e uma balança, um tubo de ensaio (para o caso de pesquisas nas áreas das ciências exatas e biológicas) mas também um formulário, um questionário, ou mesmo um gráfico que se elabora para acondicionar os dados colhidos e prepará-los para a interpretação.

Já uma 'técnica' remete ao modo de realizar algo, e abrange procedimentos como as coletas de informações, as entrevistas, as maneiras sistematizadas de empreender observações, e também as análises de conteúdo, as análises estatísticas, ou outras metodologias destinadas à interpretação dos dados que foram coletados ou captados. Enfim, as "técnicas" podem se referir tanto à coleta de dados e à constituição de documentação, como também às análises destes dados e destas fontes.

Os instrumentos e técnicas são habitualmente acondicionados em um capítulo bastante importante do Projeto, e que se denomina "Metodologia" (5), "Métodos e Técnicas", "Procedimentos Metodológicos", ou algo do gênero. Também é utilizada, talvez de maneira ainda mais apropriada, a designação "Materiais e Metodologia" ("Fontes e Metodologia", por exemplo, para o caso da História). É uma designação interessante quando o pesquisador precisa descrever também os materiais sobre os quais irá trabalhar - materiais que não são propriamente aparelhos e ferramentas, mas sim a matéria-prima que sofrerá a intervenção das ferramentas e instrumentais diversos.

No caso da História, para dar o exemplo de uma das ciências humanas, esta espécie de matéria-prima fundamental da qual precisará partir o historiador que empreende a sua viagem ao passado é a "fonte" ou o "documento histórico". É conveniente dissertar sobre as "fontes" que serão utilizadas, antes de discorrer sobre as metodologias que serão utilizadas para constituí-las em um corpus documental definido e para interpretá-las. Daí ser bastante comum a designação 'Fontes e Metodologia' em um Projeto de História (equivalente a 'Materiais e Metodologia' em projetos experimentais vinculados ao campo das ciências exatas).

Deve-se acrescentar que a Metodologia, para muito além do mero registro dos materiais e técnicas, deve apresentar essencialmente a caracterização da abordagem que a pesquisa pretende utilizar em seu desenvolvimento, considerando o problema e seus objetivos. Neste sentido, a Metodologia pressupõe todo um referencial ontológico, epistemológico do pesquisador.

“A partir de que diálogos?" é a pergunta que situa uma Pesquisa em uma rede de intertextualidades com outros autores. Dito de outra forma, indaga-se aqui pelos "interlocutores" da reflexão a ser realizada. Dificilmente uma pesquisa científica parte do "ponto zero" (se é que já existiu alguma que o tenha feito na história do conhecimento humano). Nem que seja para contestar radicalmente os autores precedentes que já se debruçaram sobre o mesmo problema, o pesquisador precisa inserir a sua reflexão em um diálogo implícito ou explícito com a literatura e com o conhecimento já existente. Mais comum é que, além das eventuais contestações e correções a autores precedentes, o pesquisador também encontre autores e obras que lhe servirão como pontos de apoio, como alavancas para se impulsionar para mais adiante, como inspiração para novos rumos e abordagens.

É neste sentido que, em um Projeto de Pesquisa, não pode faltar o que se poderia 
chamar de uma "Revisão Bibliográfica". Alguns modelos de Projeto atribuem um capítulo especial a este levantamento crítico, no qual o pesquisador irá apresentar e discutir algumas das obras preexistentes que serão reapropriadas no seu trabalho, seja sob a forma de assimilação ou de confronto. Mas, por outro lado, o já mencionado "Quadro Teórico", que vimos ser aquele capítulo em que o pesquisador expõe o seu referencial teórico e os conceitos de que irá se valer, pode também incluir como item a revisão bibliográfica, já que, de algum modo, esta revisão também representa uma base de teoria da qual partirá o pesquisador para elaborar as suas próprias reflexões.

O importante é que este item (ou o seu conteúdo) esteja efetivamente presente, embora sem repetições. Portanto, se foi destacado um capítulo especial para a "Revisão Bibliográfica" (que muitas vezes aparece logo depois da "Introdução" ou a da "Delimitação Temática") as obras ali mencionadas não devem ser rediscutidas no "Quadro Teórico". É possível também discutir algumas obras na "Revisão Bibliográfica", mais diretamente ligadas ao tema, e deixar para o "Quadro Teórico" a discussão de outras que se referem mais propriamente a instrumentais teóricos que serão utilizados, a conceitos importantes para a pesquisa, a categorias e abordagens.

Quando o Projeto de Pesquisa delimita um capítulo especial para a "Revisão Bibliográfica", logo depois da apresentação do tema e da definição da problemática, esta oportunidade deve ser aproveitada para apresentar as lacunas existentes no conhecimento sobre o assunto que será abordado. Tornar claras as lacunas bibliográficas relativas ao enfoque proposto, por sinal, é um excelente elo de ligação para o item "Justificativa", que pode principiar precisamente ressaltando que, dadas as lacunas ainda existentes neste ou naquele aspecto, o Projeto proposto torna-se extremamente relevante, já que poderá contribuir de alguma maneira para suprí-las. Com isto, o pesquisador já parte com um excelente argumento a favor da necessidade de a sua pesquisa ser empreendida.

Não é necessário, por outro lado, discutir toda a bibliografia que existe sobre o assunto.
Isto seria exaustivo, quando não impossível. Algumas obras podem apenas ser referenciadas no compartimento final do Projeto, a "Bibliografia" ou "Referências Bibliográficas" (8). Outras obras, consideradas pouco importantes para a pesquisa, sequer precisam aparecer. O que não pode faltar são as fontes mais diretas, que no caso de uma pesquisa historiográfica, por exemplo, são os chamados "documentos" ou "fontes históricas". Estas "fontes primárias", aliás, devem aparecer separadas da "bibliografia geral", precedendo-a. Ou seja, no caso dos projetos de História o capítulo "Bibliografia" deve ser organizado em dois itens distintos, um relativo à documentação de época ou mais diretamente assimilada como material primário pertinente ao problema examinado, e outro relacionado às obras de autores vários que refletiram sobre o mesmo tema, e que constituem o diálogo intertextual estabelecido pela Pesquisa.

"Quando fazer?" é a pergunta que remete à temporalidade relacionada à duração da pesquisa, ao planejamento das suas várias etapas. Toda pesquisa deve ser proposta em relação a um intervalo de tempo definido, mesmo que passível de renovação. Freqüentemente, ela será realizada por etapas, e se abranger um período relativamente amplo (um ano ou mais) será necessário dar à Instituição satisfações periódicas a respeito do andamento da Pesquisa, o que poderá ser feito com a utilização de um tipo de texto que é chamado "Relatório de Pesquisa".

Com relação ao Projeto, as várias etapas previstas, as várias atividades que serão realizadas, os diferentes trabalhos que integrarão a pesquisa - tudo isto precisa ser referenciado em um "Cronograma de Pesquisa", normalmente sob a forma de um quadro ou tabela que expõe de maneira instantânea a relação entre o conjunto de ações previstas e o tempo previsto para serem realizadas. O Cronograma é um instrumento não apenas para o controle da Instituição, mas principalmente para o autocontrole do pesquisador no que se refere ao andamento do seu trabalho. Ele não é, naturalmente, uma tábua sagrada e implacável, mas é uma orientação importante para a realização do trabalho. 
Será oportuno mencionar um capítulo recorrente em Projetos que é aquele que se relaciona às "Hipóteses" e que, normalmente, vem situado após o "Quadro Teórico" e antes do capítulo relacionado à "Metodo-logia". De certo modo, as hipóteses constituem o verdadeiro cerne da pesquisa do tipo "tese". Veremos adiante que uma hipótese corres-ponde a uma resposta (ou possibilidade de resposta) que se relaciona ao problema formulado. Dependendo da intencionalidade da Pesquisa, seu problema e objetivos, pode-se ainda recorrer ao uso de 'Questões Norteadoras de Pesquisa' em substituição às Hipóteses, o que, naturalmente, também implica diferenciação de procedimentos de coleta e análise dos dados ou informações.

Retomando o esclarecimento relacionado à função de hipóteses em certos tipos de pesquisa, deve-se ressaltar que uma hipótese representa uma direção que se imprime à Pesquisa, mesmo que seja abandonada no decorrer do processo de investigação em favor de outra. Ao mesmo tempo em que deve estar intimamente relacionada ao "Quadro Teórico", as hipóteses também contribuem para definir a "Metodologia" que será empregada. Desta forma, as hipóteses preenchem um certo espaço entre a teoria e a metodologia de um Projeto de Pesquisa, razão por que se prefere localizá-la entre estes dois capítulos.

De certo modo, é somente quando se consegue elaborar uma ou mais hipóteses de trabalho que a Pesquisa começa a tomar a forma requerida a uma Dissertação de Mestrado ou a uma Tese de Doutorado. Caso contrário, tem-se apenas um trabalho descritivo, que pode ser adequado a uma Monografia ou a um Livro que se proponha a desenvolver determinado assunto, mas que não corresponde propriamente ao modelo de tese. Uma tese não é uma reflexão livre, descritiva ou ensaística, mas sim uma reflexão sistematizada e orientada por um determinado problema.

Por outro lado, vale lembrar que nem toda Pesquisa corresponde necessariamente a um modelo de Tese, e pode se dar que o objetivo do pesquisador seja apenas o de levantar determinado conjunto de dados ou de informações. Este tipo de pesquisa é em diversas ocasiões requerido por empresas que precisam se manter informadas para definir suas linhas de ação. Pode-se, por exemplo, encomendar uma "pesquisa de mercado", ou ainda uma "pesquisa de tendências" que vise acompanhar um processo eleitoral com tal ou qual finalidade. Pode-se visar o levantamento do perfil de determinado grupo de consumidores, ou empreender uma pesquisa descritiva que busque levantar as características de determinada localidade. Neste caso, se o Projeto de Pesquisa do qual estamos falando não é um projeto problematizado no modelo de tese, obviamente não tem sentido um capítulo relativo a "Hipóteses".

Em linhas gerais, as partes acima descritas compõem a totalidade do Projeto de Pesquisa, podendo ainda ser incluído um capítulo relacionado a "Recursos" para o caso de serem requeridos a determinada instituição financiamentos diversos, equipamentos, passagens, e também a contratação de pessoal técnico. O capítulo "Recursos", que pode abranger um plano de custos da pesquisa e uma exposição de suas necessidades materiais, estaria respondendo a uma nova pergunta: "Quanto vai custar?".

Pode-se dar, ainda, que para além dos recursos econômicos e materiais seja necessário planejar diversificados recursos humanos. Neste caso, estaremos falando de uma pesquisa que não será empreendida por uma só pessoa, mas por uma equipe que poderá ser coordenada pelo autor do Projeto. Trata-se, neste caso, de planificar a contribuição e atuação de todos os participantes, e de indicar eventualmente entidades que estejam atuando em conjugação com o Projeto. Em uma palavra, trata-se de responder às perguntas "Quem vai fazer?" e "O que cada um vai fazer?".

Estes últimos aspectos, naturalmente, fogem ao caso dos Projetos de Dissertação ou de Tese, que implicam, necessariamente, trabalhos individuais. Quanto aos demais aspectos, correspondem ao tipo de conteúdo que deve aparecer em qualquer espécie de Projeto ao qual se queira dar um tratamento minimamente profissional. Para sintetizar o 
que já foi dito, o quadro 3 procura relacionar as várias perguntas que se faz a um Projeto com os seus capítulos correspondentes.

\begin{tabular}{|l|l|}
\hline & Introdução \\
\hline Quem fará? & $\begin{array}{l}\text { Descrição de pessoal, se houver (senão, este item } \\
\text { é suprido pelo registro do nome do autor na folha } \\
\text { de rosto) }\end{array}$ \\
\hline O que fazer? & Delimitação temática e formulação do problema \\
\hline $\begin{array}{l}\text { Dialogando } \\
\text { Com quem? }\end{array}$ & Revisão Bibliográfica \\
\hline Por que fazer? & Justificativa \\
\hline Para que fazer? & Objetivos \\
\hline Com que fundamentos? & Quadro teórico \\
\hline Com que materiais? & Fipóteses \\
\hline Com que instrumentos? metodologia & Fontes e metodologia \\
\hline De que modo fazer? & Fontes e metodologia \\
\hline Quando Fazer? & Cronograma \\
\hline Com que recursos? & Recursos e aspectos orçamentários \\
\hline & Bibliografia \\
\hline
\end{tabular}

Quadro 3 - Perguntas de um projeto e capítulos correspondentes

Por outro lado, embora os vários tipos de conteúdo atrás descritos marquem uma presença quase certa, deve ficar claro que não existe um parâmetro oficial e único de Projeto de Pesquisa no que tange à sua ordem e definição de capítulos. Partindo do modelo proposto, o pesquisador pode considerar adequado suprimir ou acrescentar capítulos, reunir duas seções em uma única, modificar a ordem de apresentação dos capítulos propostos, e assim por diante - desde que isto faça algum sentido para a sua pesquisa ou que atenda a um padrão qualquer de lógica proposto pelo próprio autor do projeto. De igual maneira, um tipo de pesquisa ou um campo de conhecimento específico pode exigir a abertura de um capítulo que não seria necessário, ou mesmo pertinente, em outro. Enfim, qualquer modelo de Projeto proposto em uma obra de Metodologia Científica não é mais que isto: um modelo, pronto para ser alterado e adaptado de acordo com as necessidades.
Outro ponto que se mostra oportuno esclarecer é a distinção entre o Projeto e a Pesquisa propriamente dita, ou ainda entre o Projeto e a própria Tese ou Monografia que registrará os resultados da pesquisa. Um projeto é uma proposta de realizar algo, é um roteiro, um instrumento de planejamento. Sua linguagem, ou pelo menos sua intenção, está associada a um tempo verbal no futuro. Já a Tese, a Monografia ou qualquer outro tipo de texto no qual o pesquisador registra o resultado de sua pesquisa e a sua reflexão, corresponde um trabalho já realizado e concluído. É a Tese, ou a Monografia, o que poderá se transformar eventualmente em livro, não o Projeto. Em vista disto, a linguagem da tese refere-se a uma pesquisa já realizada, enquanto a do Projeto refere-se a uma Pesquisa por se realizar.

Desta maneira, se em algumas ocasiões é possível aproveitar para o texto da Tese ou Monografia trechos que haviam sido escritos originalmente para o seu Projeto de Pesquisa (um quadro teórico ou metodológico, uma revisão bibliográfica) deve-se ter o cuidado de adaptar a linguagem do 'futuro ainda não realizado' que aparece no Projeto para a linguagem do 'passado já realizado', da pesquisa já concluída exposta na Tese.

Por fim, acrescentaremos que o modelo de Projeto de Pesquisa atrás discutido, em suas instâncias fundamentais, pode ser utilizado de maneira eficaz para a maioria dos campos de conhecimento, sejam os pertencentes ao universo das ciências humanas, sejam os pertencentes ao universo das ciências exatas e biológicas.

\section{Referência}

BARROS, José D’Assunção. O Projeto de Pesquisa em História. 4. ed. Petrópolis: Vozes, 2008 . 
